\title{
Ambient measurement of fluorescent aerosol particles with a WIBS in the Yangtze River Delta of China: potential impacts of combustion-related aerosol particles
}

\author{
Xiawei Yu ${ }^{1,2}$, Zhibin Wang ${ }^{2}$, Minghui Zhang ${ }^{2}$, Uwe Kuhn $^{2}$, Zhouqing Xie ${ }^{1}$, Yafang Cheng ${ }^{2}$, Ulrich Pöschl ${ }^{2}$, and \\ Hang $\mathrm{Su}^{2}$ \\ ${ }^{1}$ School of Earth and Space Sciences, University of Science and Technology of China, Hefei 230026, China \\ ${ }^{2}$ Multiphase Chemistry Department, Max Planck Institute for Chemistry, Mainz 55128, Germany
}

Correspondence to: Zhibin Wang (zhibin.wang@mpic.de) and Zhouqing Xie (zqxie@ustc.edu.cn)

Received: 15 March 2016 - Published in Atmos. Chem. Phys. Discuss.: 17 March 2016

Revised: 29 July 2016 - Accepted: 23 August 2016 - Published: 13 September 2016

\begin{abstract}
Fluorescence characteristics of aerosol particles in a polluted atmosphere were studied using a wideband integrated bioaerosol spectrometer (WIBS-4A) in Nanjing, Yangtze River Delta area of China. We observed strong diurnal and day-to-day variations of fluorescent aerosol particles (FAPs). The average number concentrations of FAPs $(1-15 \mu \mathrm{m})$ detected in the three WIBS measurement channels (FL1: $0.6 \mathrm{~cm}^{-3}$, FL2: $3.4 \mathrm{~cm}^{-3}$, FL3: $2.1 \mathrm{~cm}^{-3}$ ) were much higher than those observed in forests and rural areas, suggesting that FAPs other than bioaerosols were detected. We found that the number fractions of FAPs were positively correlated with the black carbon mass fraction, especially for the FL1 channel, indicating a large contribution of combustion-related aerosols. To distinguish bioaerosols from combustion-related FAPs, we investigated two classification schemes for use with WIBS data. Our analysis suggests a strong size dependence for the fractional contributions of different types of FAPs. In the FL3 channel, combustion-related particles seem to dominate the $1-2 \mu \mathrm{m}$ size range while bioaerosols dominate the $2-5 \mu \mathrm{m}$ range. The number fractions of combustion-related particles and noncombustion-related particles to total aerosol particles were $\sim 11$ and $\sim 5 \%$, respectively.
\end{abstract}

\section{Introduction}

From the beginning of atmospheric aerosol studies, airborne biological particles have been found as an important class of aerosol particles (Bary et al., 1887; Després et al., 2012; Fröhlich-Nowoisky et al., 2016). They are ubiquitous in the atmosphere with a wide size range from approximately several nanometers to a few hundred micrometers (Pöschl, 2005; Després et al., 2012). Primary biological aerosol particles (PBAPs) are a subset of biological particles, usually defined as the aerosols of biological origin or carry living organisms, including viruses, bacteria, fungal, pollen, cell or plant debris, and animal tissue (Huffman et al., 2012; FröhlichNowoisky et al., 2016). PBAPs can affect the Earth's radiation balance directly by absorbing and scattering solar radiation, and indirectly by serving as giant cloud condensation nuclei (CCN) and ice nuclei (IN), and thereby influence cloud microphysical and climate-relevant properties (Christner et al., 2008; Pöschl et al., 2010; Deleon-Rodriguez et al., 2013; Morris et al., 2013). These impacts are not only restricted to a local scale, but also may be effective in a regional scale due to the transport of bioaerosols, e.g., by dust storms (Griffin, 2007; Polymenakou et al., 2008; Hallar et al., 2011; Creamean et al., 2013). In addition, PBAPs can spread human, animal, and plant disease and influence public health (Després et al., 2012; Cao et al., 2014). Considering its comprehensive impacts in diverse scientific fields, a better understanding of PBAPs such as its concentration, composition, and spatial and temporal variability becomes critically important. 
Table 1. Definition of abbreviations used in the text.

\begin{tabular}{ll}
\hline Short name & Description \\
\hline PBAPs & Primary biological aerosol particles \\
FAPs & Fluorescent aerosol particles \\
FL1 & Fluorescent particles detected in channel FL1_280 (excitation at 280 nm, detection 310-400 nm) \\
FL2 & Fluorescent particles detected in channel FL2_280 (excitation at 280 nm, detection 420-650 nm) \\
FL3 & Fluorescent particles detected in channel FL2_370 (excitation at 370 nm, detection 420-650 nm) \\
Type A & Fluorescent particles detected in channel FL1 only \\
Type B & Fluorescent particles detected in channel FL2 only \\
Type C & Fluorescent particles detected in channel FL3 only \\
Type AB & Fluorescent particles detected in channels FL1 and FL2 \\
Type AC & Fluorescent particles detected in channels FL1 and FL3 \\
Type BC & Fluorescent particles detected in channels FL2 and FL3 \\
Type ABC & Fluorescent particles detected in channels FL1, FL2 and FL3 \\
$N_{x}$ & Number concentration of each type particles \\
$F_{x}$ & Number fraction of each type particles \\
$M_{\mathrm{BC}}$ & Mass concentration of black carbon \\
PM & Mass concentration of particles in the size range of 0.006-0.8 $\mu \mathrm{m}$ \\
$D_{\mathrm{o}}$ & Optical diameter \\
a.u. & Arbitrary units \\
\hline
\end{tabular}

Despite its importance, information of PBAPs in the atmosphere is still very limited. Further investigation is hindered due to the lack of automatic measurement techniques. Most previous studies are based on the analysis of cultivable PBAPs or DNA (deoxyribonucleic acid) from filter samples (Henningson and Ahlberg, 1994; Duchaine et al., 2001; Yu et al., 2013; Fröhlich-Nowoisky et al., 2016). These methods are time-consuming and their results may differ depending on the cultivation condition and procedures, especially considering the ubiquity of microorganisms that cannot be cultivated (Oliver, 2005; Pöhlker et al., 2012). The low time resolution of cultivation methods makes it difficult to investigate the emission mechanisms of PBAPs, which happen at a timescale of less than a few hours.

Since most biological materials contain fluorophores, instruments based on the fluorescence detection, such as a UVAPS (ultraviolet aerodynamic particle sizer; Brosseau et al., 2000), WIBS (wideband integrated bioaerosol spectrometer), and other custom-made instruments based on the LIF (laser induced fluorescence) technology (Pan et al., 2009; Taketani et al., 2013; Miyakawa et al., 2015), have recently been developed for online measurements of PBAPs. These instruments have been applied in various atmospheric environments, including rainforest (Gabey et al., 2010; Huffman et al., 2012), forest (Huffman et al., 2013; Schumacher et al., 2013; Crawford et al., 2014), high-altitude (Gabey et al., 2013; Valsan et al., 2016), rural (Healy et al., 2014), suburban (Huffman et al., 2010; Toprak and Schnaiter, 2013), and urban environments (Gabey et al., 2011; Miyakawa et al., 2015; Wei et al., 2016). Besides settled sampling sites, a WIBS has also been used for airborne observations (Perring et al., 2015). In clean environments, these techniques can ef- fectively distinguish PBAPs from other kinds of aerosol particles. For example, Huffman et al. (2012) found similar size distributions of PBAPs measured by UV-APS and scanning electron microscopy (SEM) in the Amazon rainforest.

PBAPs, however, are not the only fluorescent aerosol particles (FAPs) in the atmosphere. Other materials such as polycyclic aromatic hydrocarbons (PAHs) and humic-like substances (HULIS) may also fluoresce and contribute to the measured fluorescence signals (Pöhlker et al., 2012). Hence, the fluorescence information given by the instruments based on the fluorescence detection may include both fluorescent biological and non-biological particles.

In order to have a deeper insight into the ambient FAPs in a polluted area, we have performed WIBS measurements in Nanjing, China, in the autumn of 2013. In this study, we first present the number concentration of FAPs in Nanjing in comparison to previous studies. Then we demonstrate the potential impacts of combustion-related aerosol particles in discrimination of bioaerosols under the polluted atmosphere. Finally, we introduce alternative methods to quantify the relative contributions of different fluorescent materials (combustion- and bioaerosol-type particles) to FAPs.

\section{Methods and instrumentation}

\subsection{Site description}

WIBS measurements were performed at the Station for Observing Regional Processes of the Earth System (SORPES station), Xianlin campus of Nanjing University $\left(32.12^{\circ} \mathrm{N}\right.$, $\left.118.95^{\circ} \mathrm{E}\right)$. Nanjing lies in the Yangtze River Delta with a total population of 8.18 million (data of 2013), and it is a 
Table 2. Comparisons between the results of this study and previous studies. Unit for the number concentration of fluorescent particles is $\mathrm{L}^{-1}$. Numbers in parentheses are the number fractions of fluorescent particles $(\%)$.

\begin{tabular}{|c|c|c|c|c|c|c|c|}
\hline Site location & Site category & Season & $N_{\mathrm{FL} 1}$ & $N_{\mathrm{FL} 2}$ & $N_{\mathrm{FL} 3}$ & $N_{\text {FAPs }}$ & References \\
\hline Nanjing, China & sub-urban & autumn & $570(4.6)$ & $3350(25.3)$ & $2090(15.6)$ & - & This study \\
\hline Manchester, UK & urban & winter & $29(3)$ & $52(6)$ & $110(11)$ & - & Gabey et al. (2011) \\
\hline $\begin{array}{l}\text { Puy de Dôme } \\
\text { mountain, France }\end{array}$ & high-altitude & summer & $12(4.4)$ & - & $95(35.2)$ & - & Gabey et al. (2013) \\
\hline Killarney, Ireland & rural & summer & $175(0.5)$ & $95(0.3)$ & $35(0.1)$ & $15(0.05)^{\mathrm{a}}$ & Healy et al. (2014) \\
\hline Borneo, Malaysis & rainforest & summer & - & - & - & $150^{\mathrm{b}}$ & Gabey et al. (2010) \\
\hline Karlsruhe, Germany & semi-rural & 1 year & - & - & - & $31(7.3)^{b}$ & Toprak and Schnaiter (2013) \\
\hline Amazon, Brazil & rainforest & spring & - & - & - & $93(26.3)^{\mathrm{a}}$ & Huffman et al. (2012) \\
\hline Mainz, Germany & semi-urban & $\begin{array}{l}\text { summer, } \\
\text { autumn, } \\
\text { winter }\end{array}$ & - & - & - & $27(3.9)^{\mathrm{a}}$ & Huffman et al. (2010) \\
\hline Helsinki, Finland & urban & summer & - & - & - & $13(8)^{\mathrm{a}}$ & Saari et al. (2015) \\
\hline \multirow[t]{4}{*}{ Hyytiälä, Finland } & boreal forest & spring & - & - & - & $15(4.4)^{\mathrm{a}}$ & Schumacher et al. (2013) \\
\hline & & summer & - & - & - & $46(13)^{\mathrm{a}}$ & \\
\hline & & autumn & - & - & - & $27(9.8)^{\mathrm{a}}$ & \\
\hline & & winter & - & - & - & $4(1.1)^{\mathrm{a}}$ & \\
\hline \multirow[t]{4}{*}{ Colorado, USA } & rural & spring & - & - & - & $15(2.5)^{\mathrm{a}}$ & Schumacher et al. (2013) \\
\hline & & summer & - & - & - & $30(8.8)^{\mathrm{a}}$ & \\
\hline & & autumn & - & - & - & $17(5.7)^{\mathrm{a}}$ & \\
\hline & & winter & - & - & - & $5.3(3)^{\mathrm{a}}$ & \\
\hline Ghats, India & high-altitude & summer & & & & $20(2)^{\mathrm{a}}$ & Valsan et al. (2016) \\
\hline
\end{tabular}

${ }^{\mathrm{a}}$ Results of UV-APS. ${ }^{\mathrm{b}}$ Combine with the FL1 and FL3 channels.

large commercial center in the East China region. The measurement site is $\sim 20 \mathrm{~km}$ to the east of the urban center. The SORPES station is located on a hill about $40 \mathrm{~m}$ above the surroundings. Details of this station were described by Ding et al. (2013). A 0.75 inch stainless-steel tube inlet was installed $\sim 3 \mathrm{~m}$ above the roof, and sample air was dried by a vertical silica gel drier prior to entering the WIBS. Data were collected from 29 October to 15 November 2013.

\subsection{Instruments}

Measurements of FAPs were performed with a WIBS-4A. It uses the single-particle elastic scattering intensity at $535 \mathrm{~nm}$ to calculate the optical size of particles. The scattering signal is used to trigger the flash of two xenon lamps with a UV wavelength of 280 and $370 \mathrm{~nm}$, respectively. The fluorescent signals are recorded at two wavelength bands (310400 and $420-650 \mathrm{~nm}$ ). This design results in three wavelength channels: FL1 with excitation at $280 \mathrm{~nm}$ and detection 310-400 nm, FL2 with excitation wavelength at $280 \mathrm{~nm}$ and detection wavelength at $420-650 \mathrm{~nm}$, and FL3 with excitation wavelength at $370 \mathrm{~nm}$ and detection wavelength at $420-650 \mathrm{~nm}$. Respective abbreviations are listed in Table 1. During the measurement period, we used 1 and $2 \mu \mathrm{m}$ fluorescent and non-fluorescent PSL microspheres (3K-990, B0100, 4K-02 and B0200, Duke Scientific, Inc.) for calibration. The fluorescence noise threshold is defined as

$E_{\text {Threshold }}=E+3 \sigma$, where $E$ is the modal baseline and $\sigma$ is the standard deviations in each channel. Particles with fluorescence signals above the noise threshold are classified as FAPs. Singleparticle data were converted into a size distribution with a 5 min integration time and particles with an optical diameter $\left(D_{\mathrm{o}}\right)$ of $1-15 \mu \mathrm{m}$ were analyzed in this study.

Meteorological data were collected with an automatic weather station (AG1000, CAMPBEL co.). The differential mobility particle sizer (DMPS; built at Helsinki University) was used to measure the number size distribution of submicron particles between 6 and $800 \mathrm{~nm}$ mobility diameter (Herrmann et al., 2014). Particle mass concentration below $0.8 \mu \mathrm{m}\left(\mathrm{PM}_{0.8}\right)$ was calculated from the measured size distributions assuming a density of $1.6 \mathrm{~g} \mathrm{~cm}^{-3}$ (Wang et al., 2014). A 7-wavelength "Spectrum" Aethalometer (AE-31, Magee Scientific co.) was used to measure the black carbon (BC) mass concentration $M_{\mathrm{BC}}$.

\section{Results and discussion}

\subsection{Non-biological fluorescent aerosol particles}

Figure 1 shows the time series of number concentrations and fractions of FAPs during the measurement period. The number concentration of FAPs was dominated by the FL2 channel with a mean number concentration $N_{\mathrm{FL} 2}$ of $3.4 \mathrm{~cm}^{-3}$, followed by $N_{\mathrm{FL} 3}$ of $2.1 \mathrm{~cm}^{-3}$, and $N_{\mathrm{FL} 1}$ of $0.6 \mathrm{~cm}^{-3}$. These number concentrations were 1-2 orders of magnitudes higher 


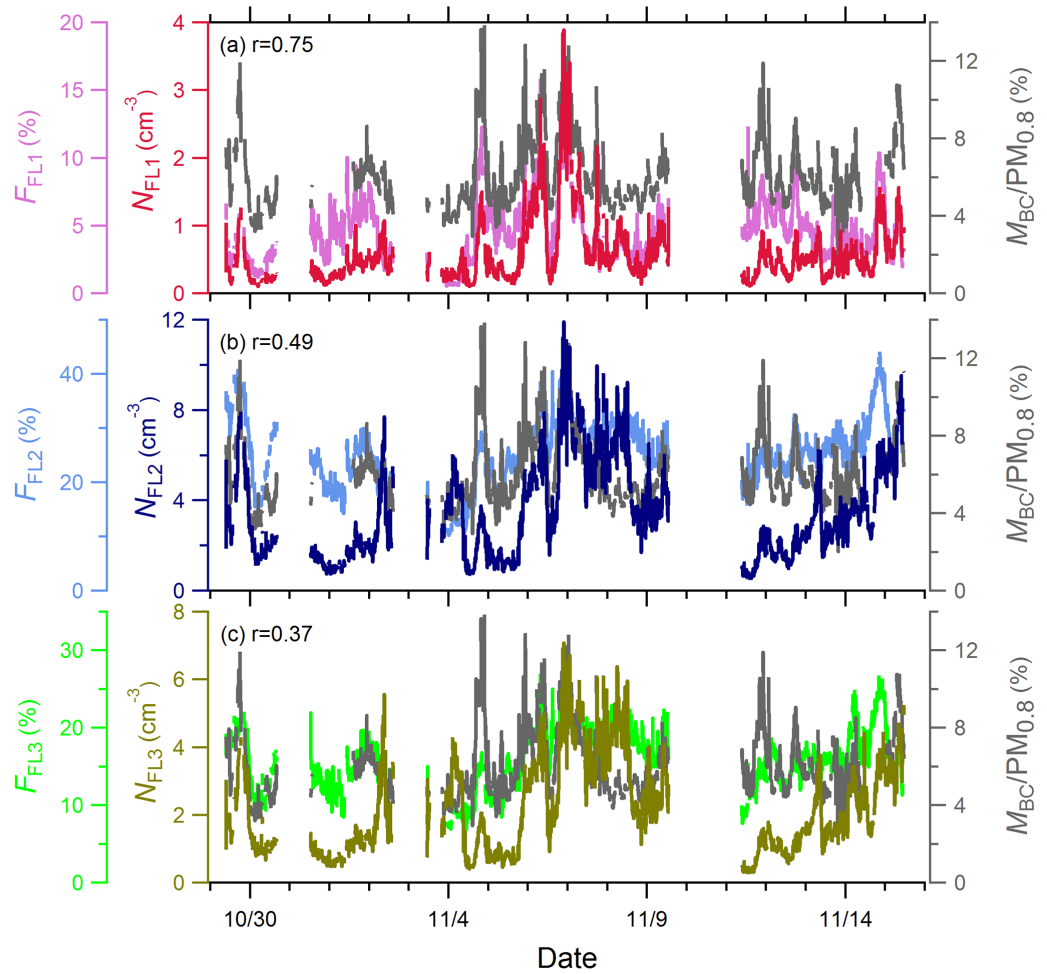

Figure 1. Time series of $M_{\mathrm{BC}} / \mathrm{PM}_{0.8}$ (gray, right axis), number concentration of fluorescent particles in each channel (primary left axis) and relative number fractions of fluorescent particles in each channel (secondary left axis). (a) FL1 channel: $N_{\mathrm{FL} 1}$ (crimson) and $F_{\mathrm{FL} 1}$ (orchid). (b) FL2 channel: $N_{\mathrm{FL} 2}$, (navy) and $F_{\mathrm{FL} 2}$ (cornflower blue). (c) FL3 channel: $N_{\mathrm{FL} 3}$ (olive) and $F_{\mathrm{FL} 3}$ (lime). $r$ is the correlation coefficient between $F_{X}$ and $M_{\mathrm{BC}} / \mathrm{PM}_{0.8}$.

than those observed in clean areas where bioaerosols dominate the FAPs (Table 2). For example, FAPs of 0.093, 0.15, and $0.023 \mathrm{~cm}^{-3}$ were reported for the Amazon, Borneo, and Hyytiälä forests, respectively (Gabey et al., 2010; Huffman et al., 2012; Toprak and Schnaiter, 2013). Since polluted areas are characterized by fewer plants and natural biological processes, fewer bioaerosols are expected compared to the forests. This much higher number concentration of FAPs observed in Nanjing suggests other kinds of FAPs being detected by a WIBS.

Previous studies (Pöhlker et al., 2012; Miyakawa et al., 2015; Perring et al., 2015) reported that non-biological compounds like PAHs, mineral dust, and HULIS can also fluoresce. Several non-biological fluorophores such as SOA (secondary organic aerosol), pyrene, humic acid, and naphthalene have fluorescent property in the same excitation and emission wavelength bands as the FL1 channel (Chang and Thompson, 2010; Pöhlker et al., 2012). These materials originate from sources different from bioaerosols. For example, PAHs enrich on the surface of soot particles from biomass burning and fuel combustion, challenging the interpretation of ambient particle fluorescence measurements.

Our sampling site is located in the vicinity of the polluted Nanjing city and is intensively affected by human activities. To check the potential influences of PAHs and combustion processes, we compared the variability of FAPs with that of $\mathrm{BC}$, on which the PAHs are often coated. To minimize the impacts of transport and boundary layer dynamics, we compared the ratio of BC and FAPs to the total particles in their respective size range, i.e., $M_{\mathrm{BC}} / \mathrm{PM}_{0.8}$ and $F_{x}$, instead of using absolute concentrations. Miyakawa et al. (2015) used factor analysis based on carbon monoxide, elemental carbon, and other markers (using concentration instead of ratio) to identify "combustion-type" and "dust-type" aerosols in urban areas. In our study, we found that $M_{\mathrm{BC}} / \mathrm{PM}_{0.8}$ showed a good correlation with the number fraction of FAPs, especially in the FL1 channel $(r=0.75$, Fig. 1$)$. For the FL2 and FL3 channels, the number fractions also nicely followed the variation of $M_{\mathrm{BC}} / \mathrm{PM}_{0.8}$ except for 8 November, which deteriorated the overall correlation. Since BC and PAHs are products of incomplete combustion, the similar variability suggests a large contribution from combustion-related aerosols to the measured FAPs, especially in the FL1 channel. Our findings strongly support the previous results (Toprak and Schnaiter, 2013; Miyakawa et al., 2015) that FAPs (FL1 channel) may come from the combustion process and anthropogenic interference. 
Table 3. Integrated number concentrations $\left(\mathrm{cm}^{-3}\right)$ of each FAPs and fractions $(\%)$ of FAPs number concentrations to the total particle number concentrations. Type AC is not listed.

\begin{tabular}{lrrrrrr}
\hline Category & 25th percentile & Mean & Median & 75th percentile & Standard deviation & Fraction \\
\hline Type A & 0.03 & 0.05 & 0.04 & 0.06 & 0.03 & 0.45 \\
Type B & 0.79 & 1.77 & 1.42 & 2.55 & 1.27 & 12.95 \\
Type C & 0.23 & 0.66 & 0.43 & 0.95 & 0.55 & 4.40 \\
Type AB & 0.07 & 0.15 & 0.11 & 0.18 & 0.12 & 1.20 \\
Type BC & 0.52 & 1.06 & 0.87 & 1.51 & 0.73 & 8.26 \\
Type ABC & 0.17 & 0.37 & 0.28 & 0.43 & 0.31 & 2.91 \\
CR-type & 0.63 & 1.45 & 1.10 & 2.11 & 1.06 & 10.50 \\
NCR-type & 0.32 & 0.64 & 0.54 & 0.83 & 0.46 & 4.69 \\
\hline
\end{tabular}

\subsection{Spectral patterns of fluorescent aerosol particles}

The complex nature of FAPs in polluted areas challenges the interpretation of ambient measurements. Different fluorophores have their characteristic excitation-emission matrices (EEMs) maps, which can be useful for discrimination of biological from non-biological FAPs (Pöhlker et al., 2012). Since a WIBS only has two excitation and emission wavebands, a high-resolution EEMs map cannot be retrieved. But we can still consider the two wavebands as low-resolution EEMs, of which the distribution (i.e., the ratio of the two wavebands) may also contain information about the nature of FAPs. For example, we can assume two kinds of fluorescent compounds I and II have different fluorescent spectra, as shown in Fig. 2a. For each compound, the integrated fluorescence intensity is determined in two wavebands by a WIBS (Fig. 2b). For qualitative analysis, a normalized EEM is often used providing the relative wavelength dependence of fluorescent materials. For a WIBS, we simply used the ratio of fluorescence intensity from different WIBS channels to represent the wavelength dependence (Fig. 2c).

Figure 3 shows the intensity distributions of aerosol particles in different fluorescence bands/channels. Due to the instrument setting, fluorescence signal intensities beyond 2200 arbitrary units (a.u.) are forced to the range of 2000 2200 a.u., regarding as saturated signal. Hence we only discussed fluorescence signal intensities below 2000 a.u. We first investigated the intensity ratio between channel FL1 and FL2, as shown in Fig. 3a. With increasing fluorescence intensity, the number concentrations sharply dropped, i.e., most of the abundant aerosol particles exhibited no or only weak fluorescence. Using the intensity ratio of FL1 to FL2 ( $\left.I_{\mathrm{FL} 1} / I_{\mathrm{FL} 2}\right)$ as a fluorescence fingerprint, we obtained two prominent groups of aerosols with $I_{\mathrm{FL} 1} / I_{\mathrm{FL} 2}$ approaching 0 or infinity. $I_{\mathrm{FL} 1} / I_{\mathrm{FL} 2} \sim 0$ means that the aerosols have a low FL1 intensity below the detection limit and a high FL2 intensity, while $I_{\mathrm{FL} 1} / I_{\mathrm{FL} 2}$ approaching infinity means the opposite. According to the detection thresholds of both FL1 and FL2 channels, we then classified the aerosol particles into four groups with FL1/FL2 above or below the detection threshold (labeled as g1 to g4 in Fig. 3). We further investigated the FL3 proper-

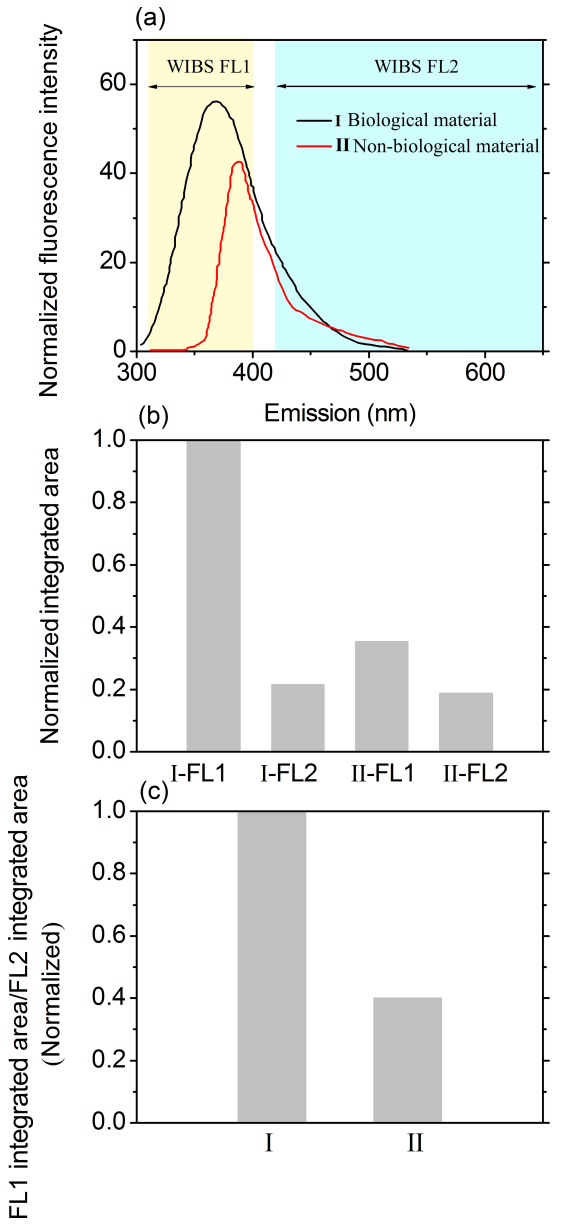

Figure 2. (a) Normalized fluorescence emission spectra of two fluorescent compounds: I (black line, biological material) and II (red line, non-biological material) for excitation wavelengths at $\lambda_{\text {ex }}=280 \mathrm{~nm}$. Shadow areas indicate the excitation wavebands of FL1 and FL2 channels of WIBS. (b) Integrated fluorescence intensity of two compounds in two bands (FL1 and FL2). (c) The ratio of fluorescence intensity from different WIBS channels $\left(I_{\mathrm{FL} 1} / I_{\mathrm{FL} 2}\right)$ of I and II compounds. The fluorescence emission spectra are obtained from Pöhlker et al. (2012). 

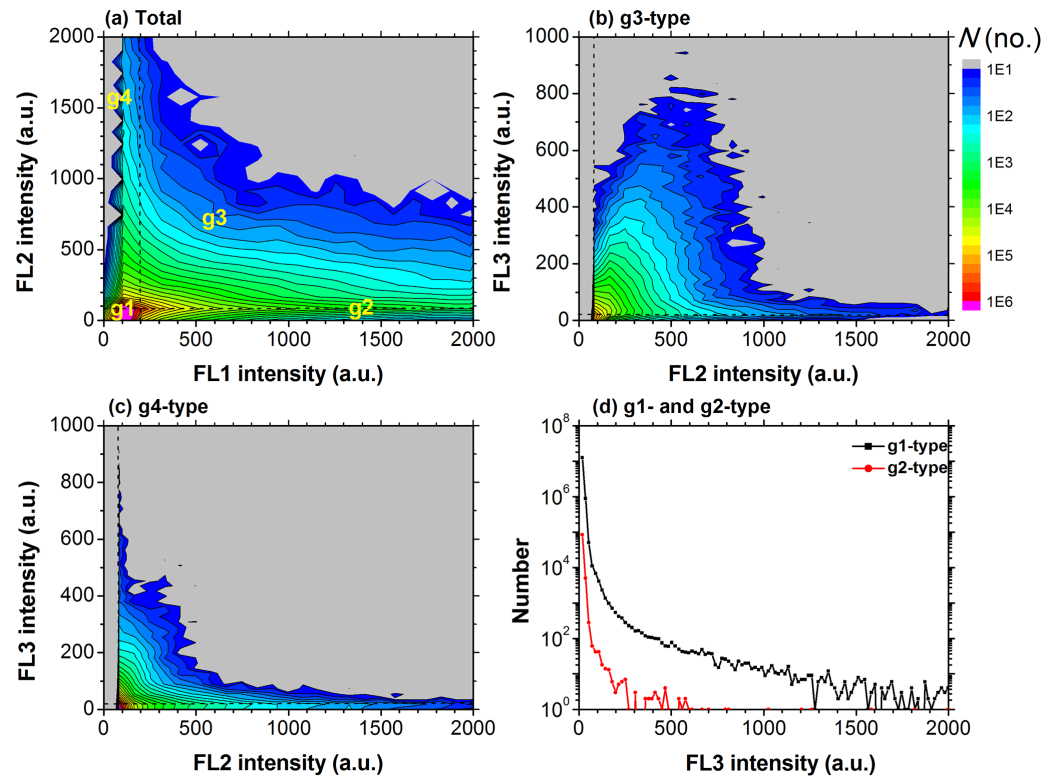

Figure 3. Spectral pattern of the classified fluorescence intensity. FL1 intensity is grouped at 100 intervals, FL2 intensity is grouped at 80 intervals, and FL3 intensity is grouped at 18 intervals. Color scale is the measured particle number. Non-fluorescent and saturating (FL $\geq 2000$ a.u.) aerosol particles were excluded. (a) FL1 intensity vs. FL2 intensity of total measured particles; (b) FL2 intensity vs. FL3 intensity of g3-type particles; (c) FL2 intensity vs. FL3 intensity of g4-type particles; (d) numbers of g1- and g2-type particles of FL3 fluorescence intensity. Because FL2 intensity of $\mathrm{g} 1$ and $\mathrm{g} 2$ are below the threshold, the spectral patterns are hence not used. Dotted lines denote the threshold of each channel (200 a.u. for FL1, 80 a.u. for FL2, and 18 a.u. for FL3).

ties of the various groups. As shown in Fig. 3b-d, the aerosol number concentration decreased as FL3 intensity increased resembling the distribution for FL1 and FL2. Similarly we used the fluorescence threshold of FL3 to classify aerosols from $\mathrm{g} 1$ to $\mathrm{g} 4$ into subgroups.

Our efforts towards a spectral fingerprint resulted in the same classification method as in Perring et al. (2015). Here we adopted the labels of Perring et al. (2015) in which channel A refers to FL1, channel B refers to FL2 and channel C refers to FL3. Any aerosol particle can have signals above/below the fluorescence threshold in any of these channels, leading to seven combinations of fluorescence signals, i.e., particles with fluorescence signals above the threshold in single channel as types A, B and C; particles with fluorescence signals in two channels as types $\mathrm{AB}, \mathrm{AC}$ and $\mathrm{BC}$ and particles with fluorescence signals in all three channels as type $\mathrm{ABC}$ (Table 1).

As shown in Fig. 4a, types B, BC and $\mathrm{C}$ were the most abundant FAPs, followed by types $\mathrm{ABC}, \mathrm{AB}$ and $\mathrm{A}$. Type $\mathrm{AC}$ had the lowest loading and was not even visible. The mean number concentrations of dominant types $\mathrm{B}, \mathrm{BC}$ and $\mathrm{C}$ were $1.77,1.06$, and $0.66 \mathrm{~cm}^{-3}$, respectively (Table 3 ). The number concentration of seven-type FAPs exhibited strong diurnal and day-to-day variability (Fig. 5). Number concentration of FAPs peaked in the morning $(\sim 08: 00$ local time $)$ and reached a minimum in the afternoon $(\sim 14: 00)$. Their similar diurnal patterns indicate the dominant effect of boundary layer development in controlling the variability of aerosol particles, which was also shown in FL1, FL2, and FL3 channels (Fig. S1 in the Supplement). To better understand the source of FAPs, we also investigated the number fraction of FAPs in total particles. The boundary layer development exerts similar effect on all kinds of aerosol particles. Thus for particles of the same origin, their ratios will remain constant and a difference in their ratios reflects their different sources. As shown in Fig. 5, the fractions of FAPs presented quite different diurnal patterns. The fractions of type BC revealed a substantial diurnal opposite with a clear morning peak and early afternoon minimum. Type A and type B showed a much weaker variability, implying a similar source of FAPs as the total aerosol particles.

The number size distributions of FAPs were shown in Fig. 6. The highest FAPs number concentration came out at $\sim 1 \mu \mathrm{m}$ except type ABC. Type ABC peaked at $1-2 \mu \mathrm{m}$ with a second peak at $4-6 \mu \mathrm{m}$. For type $A$, type $C$, and type $B C$ the number concentration monotonously decreased with increasing particle diameter. No fluorescence signals were found in FL1 and FL3 channels (corresponding to type A, type C and type AC FAPs) for the particles of size larger than $4 \mu \mathrm{m}$. On the contrary, the number fractions of FAPs generally increased as the particle size increased, reaching $\sim 100 \%$ at 3-4 $\mu \mathrm{m}$ for FL2 channel (not shown in Fig. 6). These results reveal that most coarse mode particles contain certain kinds of fluorophores.

Meanwhile, we compared the number fraction of seventype FAPs with $M_{\mathrm{BC}} / \mathrm{PM}_{0.8}$; the results indicate that the 

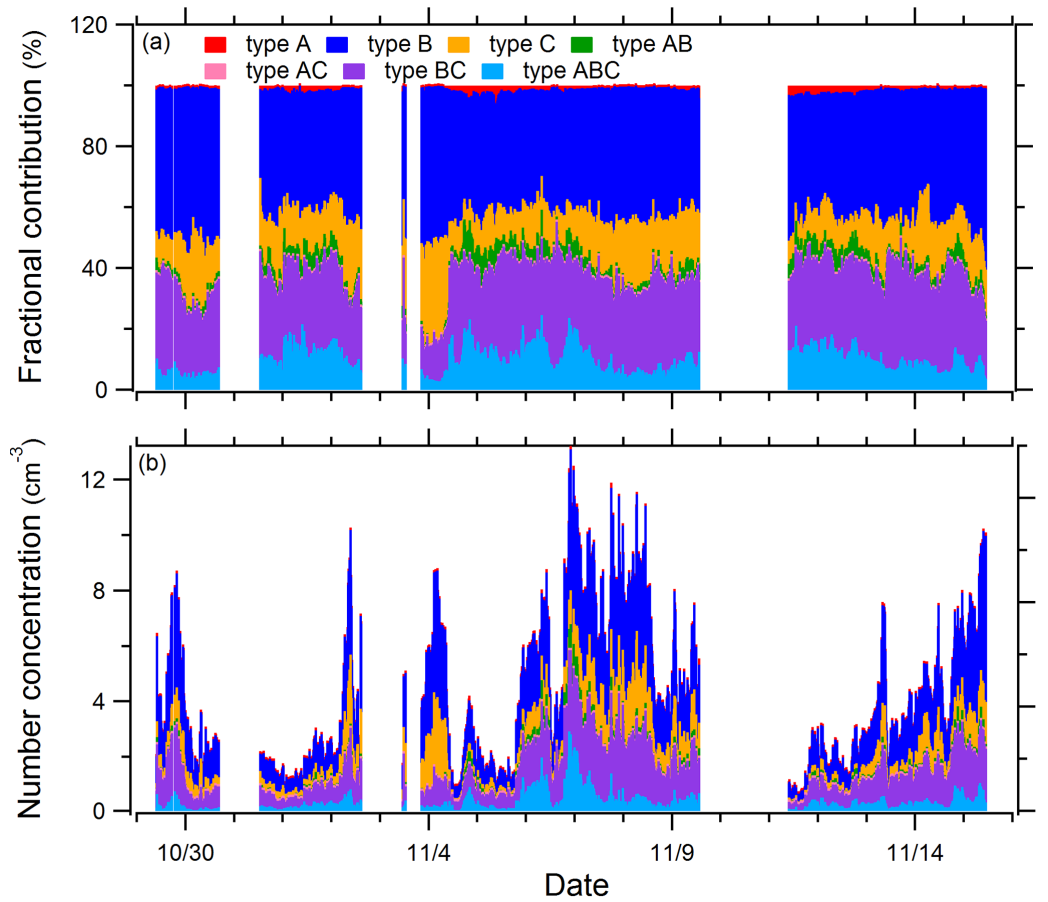

Figure 4. Time series of (a) the fractional contribution of each fluorescent type to total FAPs and (b) number concentration (left axis) of each fluorescent type. Type A: red; type B: blue; type C: dark yellow; type AB: green; type AC: pink; type BC: purple; type ABC: light blue.

number fractions of types $\mathrm{A}, \mathrm{AB}$, and $\mathrm{ABC}$ showed good correlations with $M_{\mathrm{BC}} / \mathrm{PM}_{0.8}$ (Fig. 7), suggesting a large contribution of combustion-related aerosol particles to these types. Note that all these types contain FL1 signals, implying the potential application of FL1 in the identification of biomass burning (or other combustions) events. Likewise, fluorescent types B and $\mathrm{BC}$ mostly followed the variation of $M_{\mathrm{BC}} / \mathrm{PM}_{0.8}$ except for 8 November when elevated fractional contributions were observed 1 day before a rain event on 9 November. A dramatic release of certain fungal spores was often observed before rain (Hjelmroos, 1993). However, the increase on 8 November was mainly contributed by $1-2 \mu \mathrm{m}$ FAPs rather than fungal spores $(>3 \mu \mathrm{m})$ shown by Hjelmroos (1993). So the origin of this elevated FAPs remained inconclusive. Moreover, good correlation $(r=0.58)$ between type B particles in 3-4 $\mu \mathrm{m}$ and $M_{\mathrm{BC}} / \mathrm{PM}_{0.8}$, suggesting a closer link of this peak with type B particles to the combustion process. Fluorescent type $\mathrm{C}$ showed a weak negative correlation with $M_{\mathrm{BC}} / \mathrm{PM}_{0.8}$, suggesting a minor role of combustion-related aerosols or major contribution of noncombustion-related aerosols (e.g., bioaerosols or dusts).

\subsection{Fluorescence intensity}

Besides the relative wavelength dependence, the absolute quantum yield is also one of the most important characteristics of a fluorophore. Discrepancies in the quantum yield can directly influence the fluorescence, resulting in different in- tensity levels. Thus, it is possible to use the intensity information to identify different kinds of FAPs. Huffman et al. (2012) showed that the UV-APS can be used to successfully discriminate bioaerosols from dust particles, both of which have been suggested to fluoresce (Pöhlker et al., 2012).

We first made a hypothesis that there exists a characteristic intensity value $I_{\text {cri }}$, above which most FAPs are bioaerosols. Since $I_{\text {cri }}$ cannot be directly inferred from the intensity distribution (Fig. 3), we adopted the parameter $M_{\mathrm{BC}} / \mathrm{PM}_{0.8}$ to assist our analysis. Because bioaerosols and combustionrelated FAPs are of different origins, we scanned different values for $I_{\text {cri }}$ until the corresponding FAP (of intensity $>I_{\text {cri }}$ ) fraction showed a non-positive correlation with $M_{\mathrm{BC}} / \mathrm{PM}_{0.8}$. In this study, we mainly focus on the FL3 channel since it is running in a similar excitation-emission wavelength as the UV-APS and it has been validated against other independent method. We thereby suggest that the FL3 channel can be used to discriminate bioaerosols from combustiongenerated FAPs in a similar approach. The analysis of the FL1 and FL2 channels are shown in the Supplement (Figs. S2 and S3). Figure 8 shows the averaged fractional contribution of FAPs with $I_{\mathrm{FL} 3}>I_{\text {cri }}$ at different $M_{\mathrm{BC}} / \mathrm{PM}_{0.8}$ levels. To account for the size dependence of fluorescence signals, we first classified FAPs according to the particle size. For the 1-2 $\mu \mathrm{m}$ size range, the fraction was always positively correlated with $M_{\mathrm{BC}} / \mathrm{PM}_{0.8}$ and was independent of the selection of $I_{\text {cri }}$. For the size range of 2-5 $\mu \mathrm{m}$, the FAPs showed mostly negative correlation with $M_{\mathrm{BC}} / \mathrm{PM}_{0.8}$ and were also 

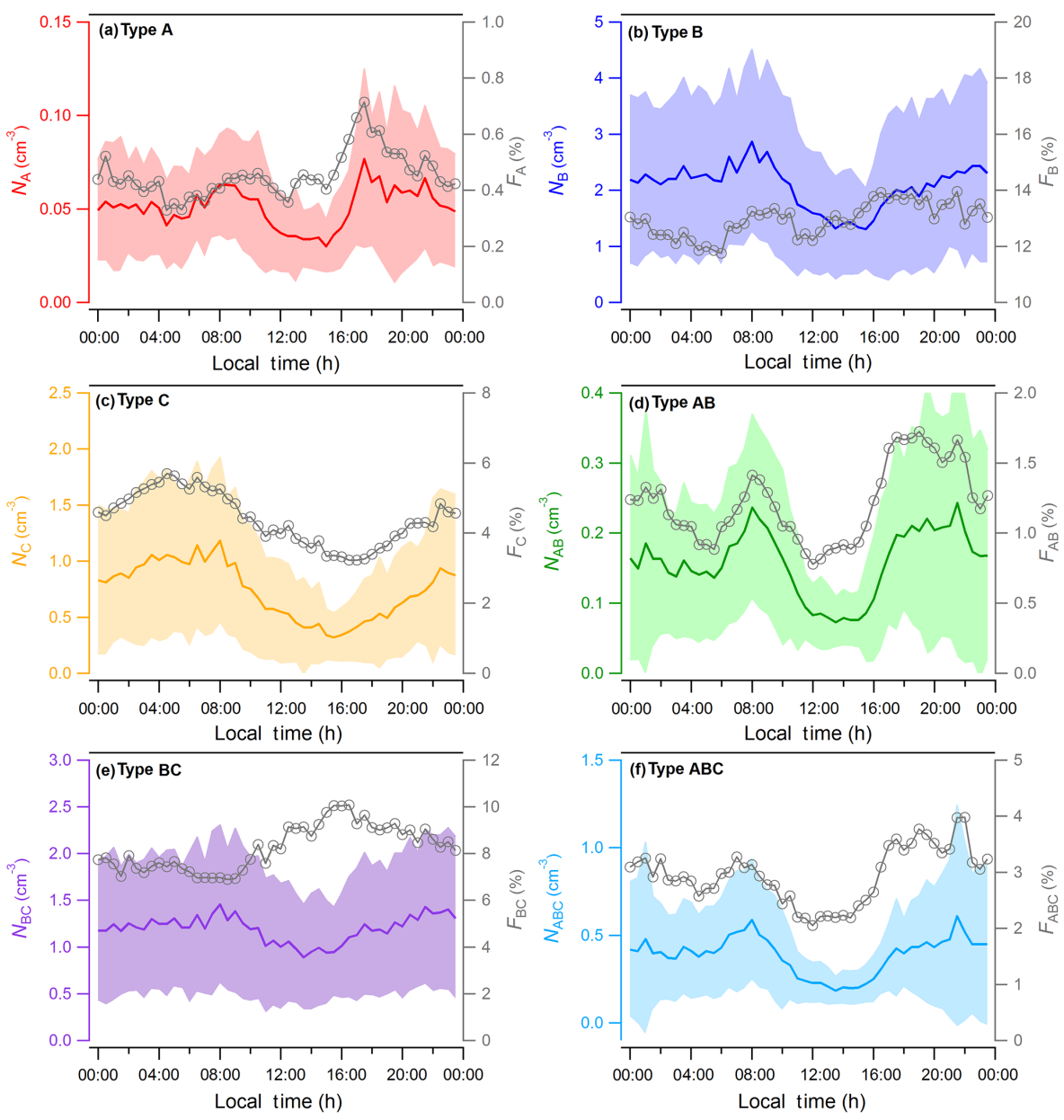

Figure 5. Diurnal variations of number concentrations of (a) type A (red), (b) type B (blue), (c) type C (dark yellow), (d) type AB (green), (e) type $\mathrm{BC}$ (purple), and (f) type $\mathrm{ABC}$ (light blue). Gray line indicates the number fraction of respective fluorescent particles (right axis). Shading indicates \pm 1 standard deviation.
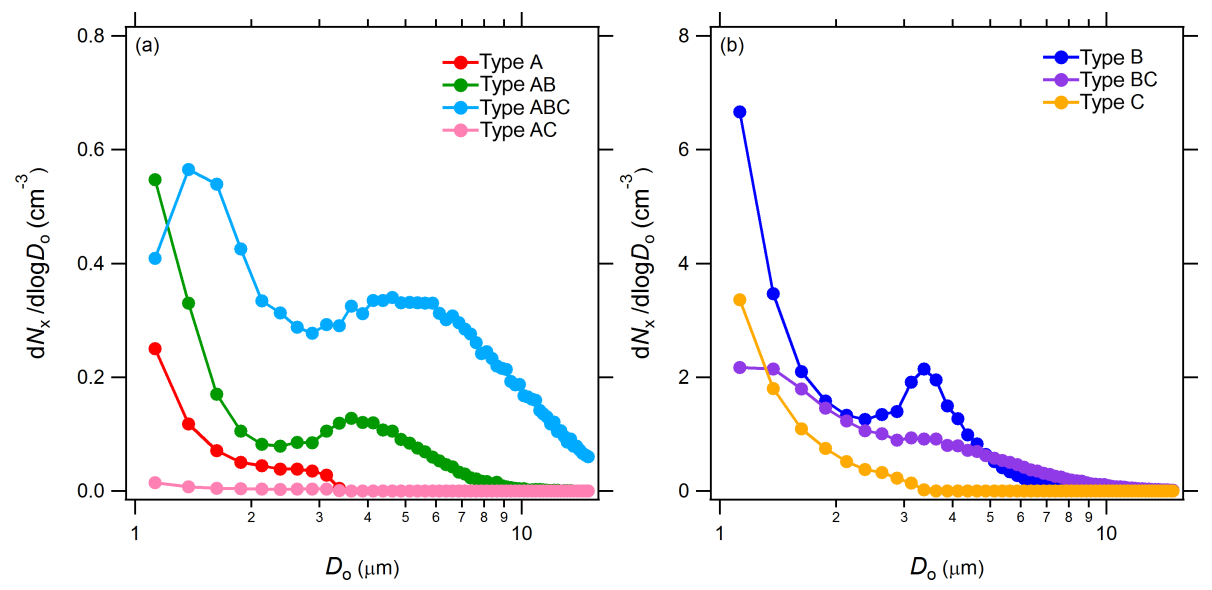

Figure 6. Mean number size distributions of (a) type A (red), type $\mathrm{AB}$ (green), type $\mathrm{AC}$ (pink), and type ABC (light blue); (b) type B (blue), type BC (purple), and type C (dark yellow). 

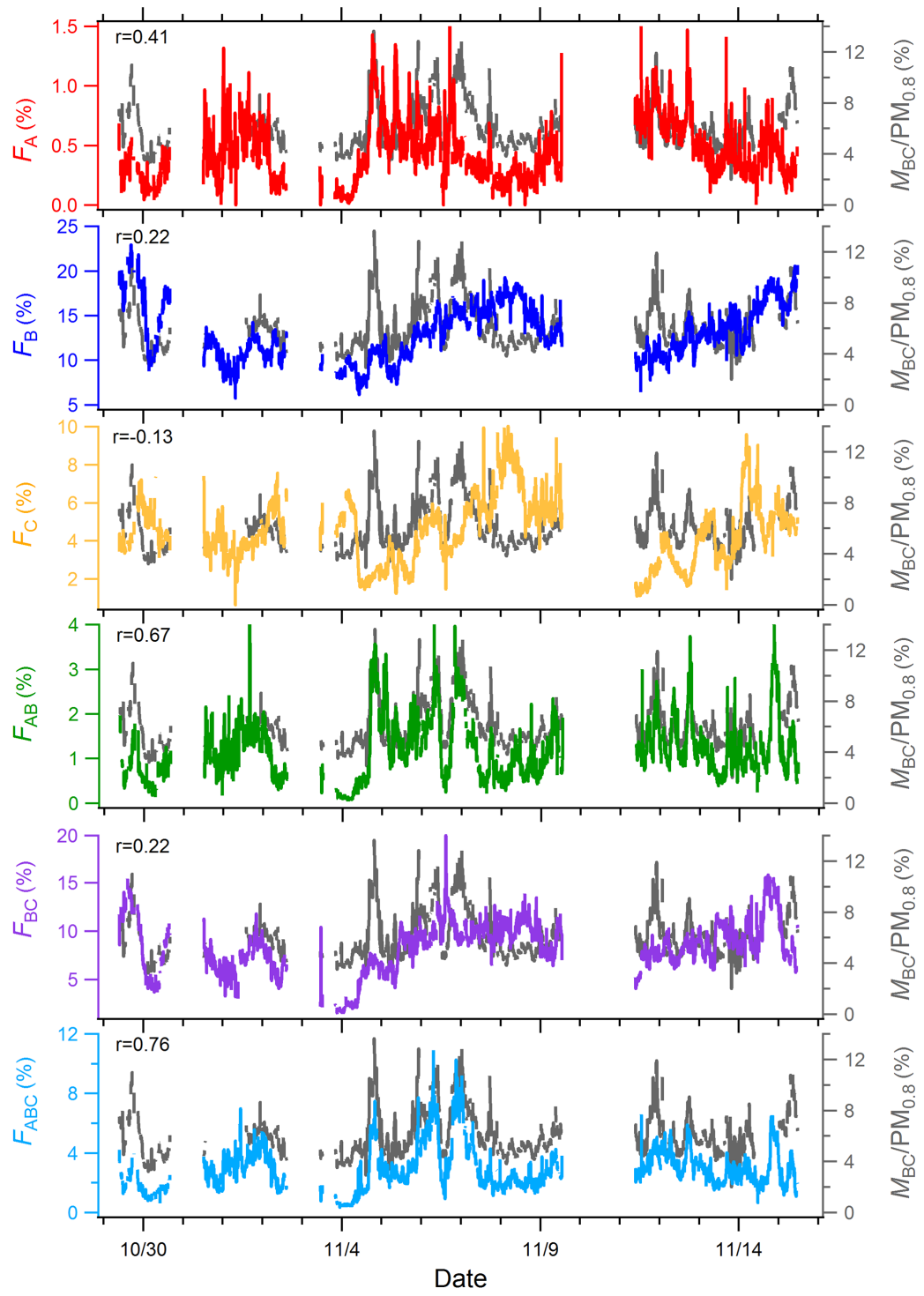

Figure 7. Time series of number fractions of various fluorescent particles (left axis) and $M_{\mathrm{BC}} / \mathrm{PM}_{0.8}$ (gray, right axis). $r$ is the correlation coefficient between $F_{x}$ and $M_{\mathrm{BC}} / \mathrm{PM}_{0.8}$.

independent of the $I_{\text {cri }}$ selection. For FAPs larger than $5 \mu \mathrm{m}$, the selection of $I_{\text {cri }}$ became critical. With increasing $I_{\text {cri }}$, the dependence of FL3 fraction on $M_{\mathrm{BC}} / \mathrm{PM}_{0.8}$ gradually became weaker and finally turned to negative at $I_{\text {cri }}>40$ a.u. The results at 5-15 $\mu \mathrm{m}$ were consistent with our hypothesis that bioaerosols have stronger fluorescence intensity than combustion-related aerosol particles and can be discriminated from their fluorescence intensity. The different correlation statistics of $1-2$ and $2-5 \mu \mathrm{m}$ may be explained by the different abundance of bioaerosols and combustion-related aerosols at a different size range. The $2-5 \mu \mathrm{m}$ mode was dominated by bioaerosols, whereas the $1-2 \mu \mathrm{m}$ mode was dominated by combustion-related aerosol particles. Therefore, there was no clear dependence on the selection of $I_{\text {cri }}$.
Saari et al. (2015) reported that FAPs at $0.5-1.5 \mu \mathrm{m}$ might be due to anthropogenic emissions such as biomass burning, while most fungal spores and pollen dominated the larger size range (Després et al., 2012). It is also possible that $I_{\text {cri }}$ had a size dependence because different types of bioaerosols may dominate different size ranges.

By integrating the FAPs of different correlations with $M_{\mathrm{BC}} / \mathrm{PM}_{0.8}$, we retrieved the number concentrations of "non-combustion-related" (NCR)-type particles (FAPs with $I_{\mathrm{FL} 3}>18$ a.u. at $2-5 \mu \mathrm{m}$ and FAPs with $I_{\mathrm{FL} 3}>40$ a.u. at 5-15 $\mu \mathrm{m})$ and "combustion-related" (CR)-type particles (FAPs with $I_{\mathrm{FL} 3}>18$ a.u. at $1-2 \mu \mathrm{m}$ and FAPs with $40 \geq I_{\text {FL3 }}>18$ a.u. at 5-15 $\mu \mathrm{m}$ ). The mean number concentrations of NCR-type and CR-type particles were $0.64 \pm 0.46$ 

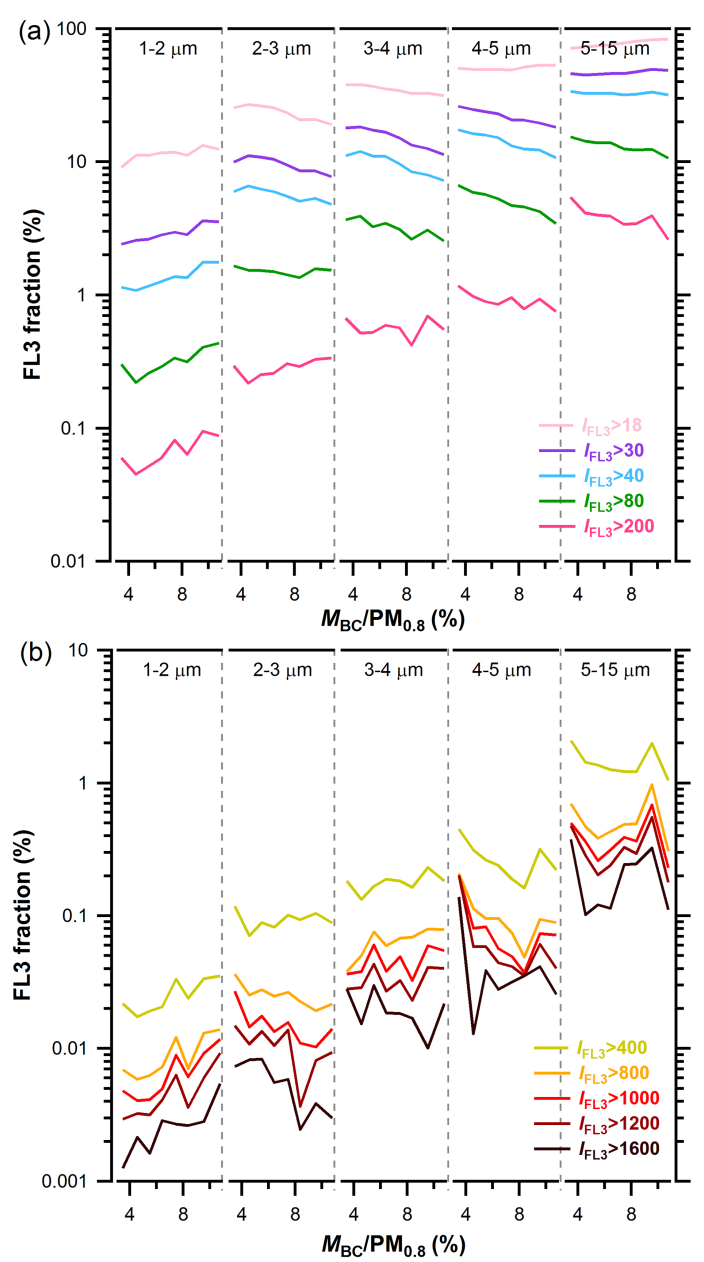

Figure 8. Correlations of FL3 fractions with $M_{\mathrm{BC}} / \mathrm{PM}_{0.8}$ in different size ranges. The FL3 fraction is the number concentration of the subgroup ratio to the number concentration of total particles in each size bin. (a) Low fluorescent intensity group. (b) High fluorescent intensity group. The color lines represent the FL3 intensity ( $\left.I_{\mathrm{FL} 3}\right)$ above the certain $I_{\text {cri }}$.

and $1.45 \pm 1.06 \mathrm{~cm}^{-3}$, respectively. The NCR-type FAPs are likely bioaerosols.

In this study, we applied two methods to classify FAPs measured by a WIBS, resulting in two non-combustion-types of particles: type $\mathrm{C}$ particles derived from fluorescence spectral pattern analysis and NCR-type particles derived from fluorescence intensity pattern analysis. As shown in Table 3, the mean number concentrations of type $\mathrm{C}$ and NCR-type particle were 0.66 and $0.64 \mathrm{~cm}^{-3}$, which were still higher than those found in PBAP-dominated regions like the Amazon (Huffman et al., 2012), Hyytiälä (Schumacher et al., 2013), and PdD (Gabey et al., 2013). This indicates that still a residual of these non-combustion-type particles may comprise other fluorescent constituents like mineral dusts (Miyakawa et al., 2015; Perring et al., 2015).

\section{Conclusions}

Online measurements of FAPs have been performed in Nanjing by using WIBS in the autumn of 2013. Our results showed that the number concentrations of FAPs were 1-2 orders of magnitudes higher than those reported in the previous studies. The observed high values suggested that directly using the FL1, FL2, and FL3 channels to index PBAPs is not suitable for polluted areas. The number fraction of FL1 showed strong correlation with $M_{\mathrm{BC}} / \mathrm{PM}_{0.8}(r=0.75)$, indicative of a strong bias by anthropogenic emissions.

In this study, we used two methods to classify the FAPs. According to the threshold of each channel, FAPs were divided into seven types. Number fraction of type $\mathrm{C}$ showed a negative correlation $(r=-0.13)$ with $M_{\mathrm{BC}} / \mathrm{PM}_{0.8}$, which might be more representative for bioaerosols. Meanwhile, on the basis of the FL3 fluorescent intensity and its correlations with $M_{\mathrm{BC}} / \mathrm{PM}_{0.8}$, FL3 fluorescent particles were divided into two types. Combustion-related-type particles seemed to dominate $1-2 \mu \mathrm{m}$, whereas the non-combustionrelated-type particles, which concentrated in the size range of 2-5 $\mu \mathrm{m}$ and showed negative correlation $(r=-0.12)$ with $M_{\mathrm{BC}} / \mathrm{PM}_{0.8}$, might have originated from biological emissions. The number concentrations of the identified two types of bioaerosols $\left(0.66 \mathrm{~cm}^{-3}\right.$ for type $\mathrm{C}$ particles and $0.64 \mathrm{~cm}^{-3}$ for non-combustion-related type), however, were still higher than those observed in clean background areas and previous studies in Nanjing (Wei et al., 2015), indicating they may also include some other fluorophores, such as dusts.

Our results suggested that fluorescence measurements in polluted areas are prone to interferences and uncertainty introduced by the anthropogenic emissions. Discrimination of biological particles from FAPs still needs further development. Each fluorophore species presents unique fluorescence spectrum; hence, we can effectively distinguish biological particles from other FAPs based on their specific EEMs maps. Due to the limitation of excitation and emission wavebands of WIBS, the development of a multi-wavebands instrument is hence needed. Other methods such as the cluster analysis (Robinson et al., 2013; Crawford et al., 2014, 2015) also exhibited the ability to differentiate various FAPs. Measuring additional particle properties such as size and morphology will help ameliorate the interferences by providing additional dimensions to distinguish fluorescent particles of different emission mechanisms.

\section{Data availability}

All the data presented in this study are available from the authors upon request (zhibin.wang@mpic.de or h.su@mpic.de).

The Supplement related to this article is available online at doi:10.5194/acp-16-11337-2016-supplement. 
Acknowledgements. This study was supported by the Max Plank Society (MPG), the European Commission under the projects BACCHUS (grant no. 603445) and the Natural Science Foundation of China (project no. 91544103). Xiawei Yu and Minghui Zhang would like to thank the China Scholarship Council (CSC) for financial support. We thank the SORPES-NJU station for logistic and instrumentation support.

The article processing charges for this open-access publication were covered by the Max Planck Society.

Edited by: A. Ding

Reviewed by: three anonymous referees

\section{References}

Bary, A., Garnsey, H. E. F., and Balfour, I. B.: Comparative morphology and biology of the fungi, mycetozoa and bacteria, Oxford, Clarendon Press, 1887.

Brosseau, L. M., Vesley, D., Rice, N., Goodell, K., Nellis, M., and Hairston, P.: Differences in Detected Fluorescence Among Several Bacterial Species Measured with a Direct-Reading Particle Sizer and Fluorescence Detector, Aerosol Sci. Tech., 32, 545558, doi:10.1080/027868200303461, 2000.

Cao, C., Jiang, W., Wang, B., Fang, J., Lang, J., Tian, G., Jiang, J., and Zhu, T. F.: Inhalable Microorganisms in Beijing's $\mathrm{PM}_{2.5}$ and $\mathrm{PM}_{10}$ Pollutants during a Severe Smog Event, Environ. Sci. Technol., 48, 1499-1507, 10.1021/es4048472, 2014.

Chang, J. L. and Thompson, J. E.: Characterization of colored products formed during irradiation of aqueous solutions containing $\mathrm{H}_{2} \mathrm{O}_{2}$ and phenolic compounds, Atmos. Environ., 44, 541-551, 2010.

Christner, B. C., Morris, C. E., Foreman, C. M., Cai, R., and Sands, D. C.: Ubiquity of Biological Ice Nucleators in Snowfall, Science, 319, 1214, doi:10.1126/science.1149757, 2008.

Crawford, I., Robinson, N. H., Flynn, M. J., Foot, V. E., Gallagher, M. W., Huffman, J. A., Stanley, W. R., and Kaye, P. H.: Characterisation of bioaerosol emissions from a Colorado pine forest: results from the BEACHON-RoMBAS experiment, Atmos. Chem. Phys., 14, 8559-8578, doi:10.5194/acp-14-8559-2014, 2014.

Crawford, I., Ruske, S., Topping, D. O., and Gallagher, M. W.: Evaluation of hierarchical agglomerative cluster analysis methods for discrimination of primary biological aerosol, Atmos. Meas. Tech., 8, 4979-4991, doi:10.5194/amt-8-4979-2015, 2015.

Creamean, J. M., Suski, K. J., Rosenfeld, D., Cazorla, A., DeMott, P. J., Sullivan, R. C., White, A. B., Ralph, F. M., Minnis, P., Comstock, J. M., Tomlinson, J. M., and Prather, K. A.: Dust and Biological Aerosols from the Sahara and Asia Influence Precipitation in the Western US, Science, 339, 1572-1578, doi:10.1126/science.1227279, 2013.

DeLeon-Rodriguez, N., Lathem, T. L., Rodriguez-R, L. M., Barazesh, J. M., Anderson, B. E., Beyersdorf, A. J., Ziemba, L. D., Bergin, M., Nenes, A., and Konstantinidis, K. T.: Microbiome of the upper troposphere: Species composition and prevalence, effects of tropical storms, and atmospheric implications, P. Natl. Acad. Sci. USA, 110, 2575-2580, doi:10.1073/pnas.1212089110, 2013.
Després, V. R., Huffman, J. A., Burrows, S. M., Hoose, C., Safatov, A. S., Buryak, G., Fröhlich-Nowoisky, J., Elbert, W., Andreae, M. O., Pöschl, U., and Jaenicke, R.: Primary biological aerosol particles in the atmosphere: a review, Tellus B, 64, 15598, doi:10.3402/tellusb.v64i0.15598, 2012.

Ding, A. J., Fu, C. B., Yang, X. Q., Sun, J. N., Zheng, L. F., Xie, Y. N., Herrmann, E., Nie, W., Petäjä, T., Kerminen, V.-M., and Kulmala, M.: Ozone and fine particle in the western Yangtze River Delta: an overview of $1 \mathrm{yr}$ data at the SORPES station, Atmos. Chem. Phys., 13, 5813-5830, doi:10.5194/acp-13-58132013, 2013.

Duchaine, C., Thorne, P. S., Mériaux, A., Grimard, Y., Whitten, P., and Cormier, Y.: Comparison of endotoxin exposure assessment by bioaerosol impinger and filter-sampling methods, Appl. Environ. Microbiol., 67, 2775-2780, 2001.

Fröhlich-Nowoisky, J., Kampf, C. J., Weber, B., Huffman, J. A., Pöhlker, C., Andreae, M. O., Lang-Yona, N., Burrows, S. M., Gunthe, S. S., Elbert, W., Su, H., Hoor, P., Thines, E., Hoffmann, T., Després, V. R., and Pöschl, U.: Bioaerosols in the Earth system: Climate, health, and ecosystem interactions, Atmos. Res., 182, 346-376, 2016.

Gabey, A. M., Gallagher, M. W., Whitehead, J., Dorsey, J. R., Kaye, P. H., and Stanley, W. R.: Measurements and comparison of primary biological aerosol above and below a tropical forest canopy using a dual channel fluorescence spectrometer, Atmos. Chem. Phys., 10, 4453-4466, doi:10.5194/acp-10-4453-2010, 2010.

Gabey, A. M., Stanley, W. R., Gallagher, M. W., and Kaye, P. H.: The fluorescence properties of aerosol larger than $0.8 \mu \mathrm{m}$ in urban and tropical rainforest locations, Atmos. Chem. Phys., 11, 5491-5504, doi:10.5194/acp-11-5491-2011, 2011.

Gabey, A. M., Vaitilingom, M., Freney, E., Boulon, J., Sellegri, K., Gallagher, M. W., Crawford, I. P., Robinson, N. H., Stanley, W. R., and Kaye, P. H.: Observations of fluorescent and biological aerosol at a high-altitude site in central France, Atmos. Chem. Phys., 13, 7415-7428, doi:10.5194/acp-13-7415-2013, 2013.

Griffin, D. W.: Atmospheric movement of microorganisms in clouds of desert dust and implications for human health, Clin. Microbiol. Rev., 20, 459-477, doi:10.1128/Cmr.00039-06, 2007.

Hallar, A. G., Chirokova, G., McCubbin, I., Painter, T. H., Wiedinmyer, C., and Dodson, C.: Atmospheric bioaerosols transported via dust storms in the western United States, Geophys. Res. Lett., 38, L17801, doi:10.1029/2011GL048166, 2011.

Healy, D. A., Huffman, J. A., O'Connor, D. J., Pöhlker, C., Pöschl, U., and Sodeau, J. R.: Ambient measurements of biological aerosol particles near Killarney, Ireland: a comparison between real-time fluorescence and microscopy techniques, Atmos. Chem. Phys., 14, 8055-8069, doi:10.5194/acp-14-80552014, 2014.

Henningson, E. W. and Ahlberg, M. S.: Evaluation of microbiological aerosol samplers: a review, J. Aerosol Sci., 25, 1459-1492, 1994.

Herrmann, E., Ding, A. J., Kerminen, V.-M., Petäjä, T., Yang, X. Q., Sun, J. N., Qi, X. M., Manninen, H., Hakala, J., Nieminen, T., Aalto, P. P., Kulmala, M., and Fu, C. B.: Aerosols and nucleation in eastern China: first insights from the new SORPES-NJU station, Atmos. Chem. Phys., 14, 2169-2183, doi:10.5194/acp14-2169-2014, 2014. 
Hjelmroos, M.: Relationship between airborne fungal spore presence and weather variables: Cladosporium and Alternaria, Grana, 32, 40-47, 1993.

Huffman, J. A., Treutlein, B., and Pöschl, U.: Fluorescent biological aerosol particle concentrations and size distributions measured with an Ultraviolet Aerodynamic Particle Sizer (UVAPS) in Central Europe, Atmos. Chem. Phys., 10, 3215-3233, doi:10.5194/acp-10-3215-2010, 2010.

Huffman, J. A., Sinha, B., Garland, R. M., Snee-Pollmann, A., Gunthe, S. S., Artaxo, P., Martin, S. T., Andreae, M. O., and Pöschl, U.: Size distributions and temporal variations of biological aerosol particles in the Amazon rainforest characterized by microscopy and real-time UV-APS fluorescence techniques during AMAZE-08, Atmos. Chem. Phys., 12, 11997-12019, doi:10.5194/acp-12-11997-2012, 2012.

Huffman, J. A., Prenni, A. J., DeMott, P. J., Pöhlker, C., Mason, R. H., Robinson, N. H., Fröhlich-Nowoisky, J., Tobo, Y., Després, V. R., Garcia, E., Gochis, D. J., Harris, E., Müller-Germann, I., Ruzene, C., Schmer, B., Sinha, B., Day, D. A., Andreae, M. O., Jimenez, J. L., Gallagher, M., Kreidenweis, S. M., Bertram, A. K., and Pöschl, U.: High concentrations of biological aerosol particles and ice nuclei during and after rain, Atmos. Chem. Phys., 13, 6151-6164, doi:10.5194/acp-13-6151-2013, 2013.

Miyakawa, T., Kanaya, Y., Taketani, F., Tabaru, M., Sugimoto, N., Ozawa, Y., and Takegawa, N.: Ground-based measurement of fluorescent aerosol particles in Tokyo in the spring of 2013: Potential impacts of nonbiological materials on autofluorescence measurements of airborne particles, J. Geophys. Res.-Atmos., 120, 1171-1185, doi:10.1002/2014jd022189, 2015.

Morris, C. E., Sands, D. C., Glaux, C., Samsatly, J., Asaad, S., Moukahel, A. R., Gonçalves, F. L. T., and Bigg, E. K.: Urediospores of rust fungi are ice nucleation active at $>-10^{\circ} \mathrm{C}$ and harbor ice nucleation active bacteria, Atmos. Chem. Phys., 13, 4223-4233, doi:10.5194/acp-13-4223-2013, 2013.

Oliver, J. D.: The viable but nonculturable state in bacteria, J. Microbiol., 43, 93-100, 2005.

Pan, Y.-L., Pinnick, R. G., Hill, S. C., and Chang, R. K.: Particle-Fluorescence Spectrometer for Real-Time SingleParticle Measurements of Atmospheric Organic Carbon and Biological Aerosol, Environ. Sci. Technol., 43, 429-434, doi:10.1021/es801544y, 2009.

Perring, A. E., Schwarz, J. P., Baumgardner, D., Hernandez, M. T., Spracklen, D. V., Heald, C. L., Gao, R. S., Kok, G., McMeeking, G. R., McQuaid, J. B., and Fahey, D. W.: Airborne observations of regional variation in fluorescent aerosol across the United States, J. Geophys. Res.-Atmos., 120, 1153-1170, doi:10.1002/2014JD022495, 2015.

Pöhlker, C., Huffman, J. A., and Pöschl, U.: Autofluorescence of atmospheric bioaerosols - fluorescent biomolecules and potential interferences, Atmos. Meas. Tech., 5, 37-71, doi:10.5194/amt-537-2012, 2012.

Polymenakou, P. N., Mandalakis, M., Stephanou, E. G., and Tselepides, A.: Particle size distribution of airborne microorganisms and pathogens during an intense African dust event in the eastern Mediterranean, Environ. Health Perspect., 116, 292-296, doi:10.1289/Ehp.10684, 2008.

Pöschl, U.: Atmospheric aerosols: Composition, transformation, climate and health effects, Angew. Chem. Int. Edit., 44, 75207540, doi:10.1002/anie.200501122, 2005.
Pöschl, U., Martin, S. T., Sinha, B., Chen, Q., Gunthe, S. S., Huffman, J. A., Borrmann, S., Farmer, D. K., Garland, R. M., Helas, G., Jimenez, J. L., King, S. M., Manzi, A., Mikhailov, E., Pauliquevis, T., Petters, M. D., Prenni, A. J., Roldin, P., Rose, D., Schneider, J., Su, H., Zorn, S. R., Artaxo, P., and Andreae, M. O.: Rainforest Aerosols as Biogenic Nuclei of Clouds and Precipitation in the Amazon, Science, 329, 15131516, doi:10.1126/science.1191056, 2010.

Robinson, N. H., Allan, J. D., Huffman, J. A., Kaye, P. H., Foot, V. E., and Gallagher, M.: Cluster analysis of WIBS single-particle bioaerosol data, Atmos. Meas. Tech., 6, 337-347, doi:10.5194/amt-6-337-2013, 2013.

Saari, S., Niemi, J., Rönkkö, T., Kuuluvainen, H., Järvinen, A., Pirjola, L., Aurela, M., Hillamo, R., and Keskinen, J.: Seasonal and Diurnal Variations of Fluorescent Bioaerosol Concentration and Size Distribution in the Urban Environment, Aerosol Air Qual. Res., 15, 572-581, 2015.

Schumacher, C. J., Pöhlker, C., Aalto, P., Hiltunen, V., Petäjä, T., Kulmala, M., Pöschl, U., and Huffman, J. A.: Seasonal cycles of fluorescent biological aerosol particles in boreal and semiarid forests of Finland and Colorado, Atmos. Chem. Phys., 13, 11987-12001, doi:10.5194/acp-13-11987-2013, 2013.

Taketani, F., Kanaya, Y., Nakamura, T., Koizumi, K., Moteki, N., and Takegawa, N.: Measurement of fluorescence spectra from atmospheric single submicron particle using laserinduced fluorescence technique, J. Aerosol Sci., 58, 1-8, doi:10.1016/j.jaerosci.2012.12.002, 2013.

Toprak, E. and Schnaiter, M.: Fluorescent biological aerosol particles measured with the Waveband Integrated Bioaerosol Sensor WIBS-4: laboratory tests combined with a one year field study, Atmos. Chem. Phys., 13, 225-243, doi:10.5194/acp-13225-2013, 2013.

Valsan, A. E., Ravikrishna, R., Biju, C. V., Pöhlker, C., Després, V. R., Huffman, J. A., Pöschl, U., and Gunthe, S. S.: Fluorescent biological aerosol particle measurements at a tropical highaltitude site in southern India during the southwest monsoon season, Atmos. Chem. Phys., 16, 9805-9830, doi:10.5194/acp-169805-2016, 2016.

Wang, H., Zhu, B., Shen, L., Liu, X., Zhang, Z., and Yang, Y.: Size distributions of aerosol during the Spring Festival in Nanjing, Huan jing ke xue, 35, 442-450, 2014 (in Chinese).

Wei, K., Zheng, Y., Li, J., Shen, F., Zou, Z., Fan, H., Li, X., Wu, C.Y., and Yao, M.: Microbial aerosol characteristics in highly polluted and near-pristine environments featuring different climatic conditions, Sci. Bull., 60, 1439-1447, doi:10.1007/s11434-0150868-y, 2015.

Wei, K., Zou, Z., Zheng, Y., Li, J., Shen, F., Wu, C.-y., Wu, Y., Hu, M., and Yao, M.: Ambient bioaerosol particle dynamics observed during haze and sunny days in Beijing, Sci. Total Environ., 550, 751-759, doi:10.1016/j.scitotenv.2016.01.137, 2016.

Yu, J., Hu, Q., Xie, Z., Kang, H., Li, M., Li, Z., and Ye, P.: Concentration and Size Distribution of Fungi Aerosol over Oceans along a Cruise Path during the Fourth Chinese Arctic Research Expedition, Atmosphere, 4, 337-348, 2013. 